\title{
The Clinical Evaluation of the Effects of Low-Level Laser Therapy on the Donor and Recipient Sites of the Free Gingival Graft: A Case Series
}

\author{
Ardeshir Lafzi ${ }^{1}$, Mahdi Kadkhodazadeh ${ }^{1,2}$, Seyed Masoud Mojahedi ${ }^{3}$, Reza Amid ${ }^{4}$, Shireen Shidfar ${ }^{2,5}$, \\ Mohammad Taghi Baghani2 ${ }^{*}$ \\ ${ }^{1}$ Department of Periodontics, Faculty of Dentistry, Shahid Beheshti University of Medical Sciences, Tehran, Iran \\ ${ }^{2}$ Dental Research Center, Research Institute of Dental Sciences, School of Dentistry, Shahid Beheshti University of Medical \\ Sciences, Tehran, Iran \\ ${ }^{3}$ Laser Application in Medical Sciences Research Center, Shahid Beheshti University of Medical Sciences, Tehran, Iran \\ ${ }^{4}$ Department of Periodontics, Dental School, Shahid Beheshti University of Medical Sciences, Tehran, Iran \\ ${ }^{5}$ Department of Periodontics, School of Dentistry, QOM University of medical sciences, QOM, Iran
}

\begin{abstract}
*Correspondence to Mohammad Taghi Baghani, Dental Research Center, Research institute of Dental Sciences, School of Dentistry, Shahid Beheshti University of Medical Sciences, Tehran, Iran Tel: +989124972695; Fax: +98212209638 Email: mtbaghani@gmail.com

Published online October 1, 2019
\end{abstract}

\begin{abstract}
Introduction: Free gingival grafting is among the most foreseeing procedures for increasing the zone of keratinized attached gingiva and enhancing soft tissue around the teeth and dental implants. Nowadays low-level laser therapy (LLLT) is a promising approach in providing patients with more pleasing results in terms of esthetics and comfort. This study aims to investigate the effects of LLLT on gingival recessions treated with free gingival graft (FGG).

Methods: This case series was conducted on 12 individuals requiring a bilateral gingival graft in the mandibular region. There was a 30-day interval between the two operations. The test side was selected randomly and irradiated by a low-level laser (LLL) just before surgery. The patients did not know which side was irradiated. LLLT was applied to the donors' as well as recipients' site immediately after the operation and 48 hours later. The patients were instructed to record their post-operative pain in a visual analogue scale (VAS) 3 and 24 hours and 7 days after the surgical procedure. The clinical photographs were taken immediately and 30 days after surgical treatment were graded by three experienced periodontists for color matching to adjacent tissues.

Results: Ten individuals could finish the study. The test group presented significantly better shade matching and wound healing at the palatal donor site on days 7, 14 and 21 . There was a significant reduction in post-operative pain after 24 hours $(P=0.007)$. No statistically significant difference was found between both groups in terms of clinical periodontal indices.

Conclusion: LLLT could reduce post-operative pain 24 hours after surgical treatment. Furthermore, the application of LLLT could improve the donors' site healing and the recipients' site color matching.

Keywords: Gingival recession; Low-level laser therapy; Wound healing.
\end{abstract}

\section{Introduction}

Gingival recession is characterized as the partial denudation of the root surface because of apical movement of the gingival margin. ${ }^{1}$ This common clinical condition can be the cause of increased susceptibility to the decay of the root surface and dentinal hypersensitivity, along with poor esthetics. ${ }^{2}$ Gingival recession is associated with the accumulation of biofilm and dental plaque, tissue inflammation, traumatic brushing, improper restoration, high frenum and muscle tension, and age. ${ }^{3,4}$ In recent decades, multiple periodontal surgeries for covering bare-root surfaces have been presented, such as laterally sliding flaps, ${ }^{5}$ coronally advanced flaps ${ }^{6,7}$ free gingival grafts (FGGs), ${ }^{5,7}$ subepithelial connective tissue grafts, ${ }^{6,8}$ acellular dermal allografts, and guided tissue regeneration. ${ }^{9}$ However, the predictability and success of these procedures can vary in different conditions, especially the initial extent and severity of recession regarding width and depth. ${ }^{10}$ Among these procedures, the FGG is one of the oldest and perhaps simplest methods, the efficiency of which has been proven in the long run. ${ }^{11-}$ ${ }^{13}$ The graft success rate depends on the remaining and the survival of the transplanted connective tissue. The formation of the fibrous tissue between the graft and the recipient bed needs several days. The full and functional integration of the graft takes approximately 17 days and

Please cite this article as follows: Lafzi A, Kadkhodazadeh M, Mojahedi SM, Amid R, Shidfar S, Baghani MT. The clinical evaluation of the effects of low-level laser therapy on the donor and recipient sites of the free gingival graft: a case series. J Lasers Med Sci. 2019;10(4):355360. doi:10.15171/jlms.2019.58. 
it can be distinguished from the surrounding tissue. ${ }^{14}$ For those with systemic diseases (such as diabetes, cancer, etc), faster wound closure is a major factor in the quality of care and their recovery. ${ }^{15,16}$

Such post-operative complications as bleeding, swelling, and pain have often been documented after mucogigival surgery ${ }^{17}$ and are associated with discomfort after surgery. ${ }^{8}$

Accelerated recovery and healing are influenced by various factors such as nutrition, vitamins, steroids, oxygen, and environmental factors. ${ }^{18}$ The low-power lasers have been utilized to accelerate and improve surgical wound healing. ${ }^{11,13-16,18,19}$ Today's low-power lasers are called soft or bio-stimulation, and their application has been recorded in the literature for more than three decades. ${ }^{15,16}$ Despite the fact that the initial studies of low-power laser therapy utilized helium-neon gas lasers $(632.8 \mathrm{~nm})$, diode lasers have received much attention in recent years. ${ }^{15}$

This clinical study aimed to evaluate the effects of lowlevel laser therapy (LLLT) on wound healing and postoperative pain following the FGGs in Miller's class I and II gingival recession.

\section{Materials and Methods}

Study Population

The sample size was determined by the power analysis based on the results from Almeida's study and under the assumption of $\alpha=0.05$ and $\beta=0.2$. The least significant difference was 0.2 , and the standard deviation was equals to 0.13 .

This study was intended as a double-blind, randomized clinical trial. The patients were selected by convenient sampling. The informed consent form, with a full and thorough description of the landscape of the study, was given to each person attending the study. Diagnosed with bilateral class I or II Miller gingival recession in the mandibular first premolar region, twelve patients (6 women and 6 men) whose ages ranged from 41 to 53 (mean age: 45.9 years) were selected from the patients visited in Periodontics Department, Dental School, Shahid Beheshti University of Medical Sciences, Tehran, Iran from December 2013 to May 2015 according to the following eligibility criteria:

\section{Inclusion Criteria}

The patients had to be 40 to 60 years old and present with Miller's Class I or II gingival recession in the premolar region. There were not any abnormalities in the palatal area. The participants signed an agreement for being a part of this study, knowing the whole landscape of it.

\section{Exclusion Criteria}

Those patients who had a history of suffering from systemic diseases, were pregnant or lactating, had a high risk for infective endocarditis, were consuming medication that could affect the finding of this study, were smoking, and had periodontal surgery done on the study zone were omitted from this study.

\section{Treatment}

All of the volunteers had been diagnosed with generalized, moderate to advanced, chronic periodontitis. The presurgical preparation was performed in all cases, which consisted of guidance and information about the causes and results of gingival recession and prevention methods. The issues linked with the causes of gingival recession, for instance, toothbrush trauma and biofilm-related inflammation, were controlled through guidelines on a standardized brushing technique to maintain a strategic distance from the impact of other hygiene methods that could cause soft tissue trauma. The patients were provided with standardized dental floss and toothbrushes. Scaling and root planing, oral hygiene, and post-operative care instructions were given. The patients were registered for operation when the plaque index of $20 \%$ or less was achieved, and the desired teeth were plaque-free.

\section{Surgical Procedure}

All of the surgeries were performed by one surgeon (A.L.) to omit inter-operative factors. Local anesthesia (2\% lidocaine with 1: 80000 epinephrine) was infiltrated in the donor and recipient area. This study used the protocol introduced by Sullivan and Atkines. ${ }^{13}$ The recipient site was prepared in a split-thickness manner and a surgical aluminum foil map was trimmed to mimic the further graft. The graft outline was determined by the use of the aluminum template. The graft thickness was about 1.5-2 $\mathrm{mm}$ and was trimmed to omit fatty tissues. The donor site was sutured to minimize the possibility of bleeding and no hemostatic agent was used. The FGG was stabilized firmly by the utilization of silk 4-0 (Supa, Iran).

According to the study design which was split-mouth and double-blind, the procedures were done with a 30-day interval for each patient. The test side was chosen at the time of performing the surgery and irradiated with a lowlevel laser. Laser irradiation simulation was performed on the control group with the probe not irradiating to minimize the risk of any bias by the patient. All the safety rules recommended by the manufacturer were followed.

The $808 \mathrm{~nm}$ diode laser (Wiser; Doctor Smile-Vicenza, Italy) was applied immediately after the surgery and it was repeated every 48 hours for three times. Irradiation was applied to achieve analgesia and also to accelerate healing. The appliance was used with the following setting: the continuous power of $50 \mathrm{~mW}$ with an energy dose of $15 \mathrm{~J} /$ $\mathrm{cm}^{2}$ for 30 seconds long on each location. To begin with, the operator applied the irradiation at $1 \mathrm{~mm}$ from the graft borders and continued the whole graft.

Immediately after the surgery and 30 days later, the operators took photographs of the recipient and donor sites (Nikon, D5200 Micro-Nikkor 105mm f/2.8G IF- 
ED, Japan). The attending individuals were instructed to describe their pain perception by means of the visual analog scale (VAS) in the extent of 0 to 10 , characterizing the minimal and maximal pain respectively, 3 and 24 hours and also 7 days after completing the grafting procedure.

Three experienced periodontists who were not involved in the study were asked to evaluate the gathered photographs. The test and control groups' pictures of the same time were presented to the periodontists, side by side without their knowing about the intervention and their judgments were scaled by the VAS from 0 to 10 of each picture in the matter of healing based on visual adaptation. The difference between the groups was measured.

All attendees were visually inspected on 7 th, 14th and 21st days after the surgery, and wound closure was measured by a standard periodontal probe (Michigan $\mathrm{O}$ probe with Williams Markings, Hu-Friedy, USA). Probing depths were recorded a month after the surgery day by a periodontal probe.

\section{Statistical Analysis}

The paired $t$ test was applied to compare the test and control groups in terms of wound closure, pain and probing depth. The McNemar test was used to analyze margin placement, and the Wilcoxon test was applied for color adaptation. For statistical analysis, SPSS 22 (SPSS Inc., Chicago, IL, USA) software was used. For all tests, the significance level was set at $P=0.05$.

\section{Results}

Ten patients ( 6 women and 4 men; $41-53$ years old; mean age: 45.9 years) completed the study.

\section{Donor Site Wound Healing}

The donor site healed faster in the test group in comparison with the control group on days 7, 14 and 21 after the surgery (see Table 1 and Figure 1).

Post-operative Pain

Twenty-four hours after surgery, the pain was significantly lower in the test group compared to the control group $(P=0.007)$; however, 3 hours and 7 days after surgery, there was no significant difference between the 2 groups $(P=0.343)$ (Table 2 and Figure 2$)$.

Bleeding on Probing After the Surgery

Among all participants, in either the test group or the

Table 1. Mean Percentage of Donor Site Healing in the Test and Control Groups

\begin{tabular}{lccc}
\hline & Control Group & Test Group & $\boldsymbol{P}$ Value \\
\hline $7^{\text {th }}$ day after surgery & $37 \%$ & $43 \%$ & 0.000 \\
$14^{\text {th }}$ day after surgery & $51 \%$ & $61 \%$ & 0.000 \\
$21^{\text {st }}$ day after surgery & $78 \%$ & $87 \%$ & 0.000 \\
\hline
\end{tabular}

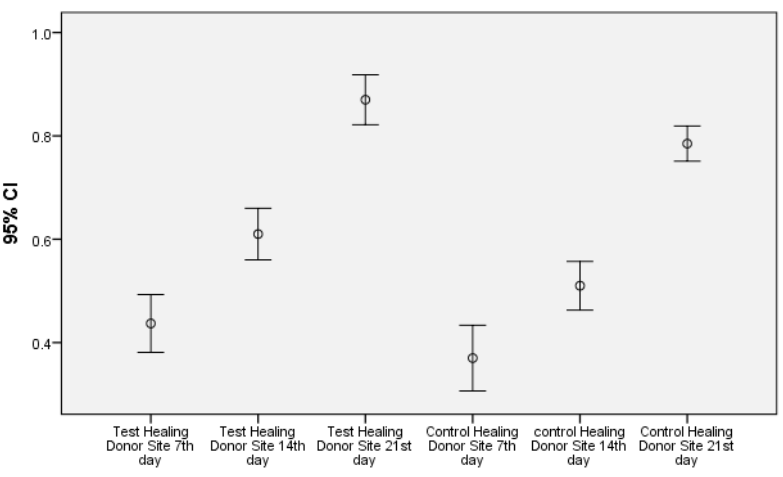

Figure 1. Wound Healing in Donor Site in the Test and Control Groups

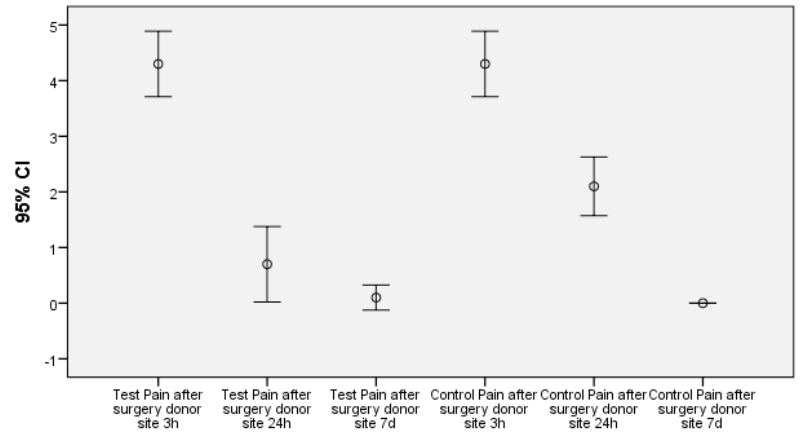

Figure 2. Pain and Discomfort After the Surgery in the Test and Control Groups.

control group, there was no bleeding on probing before and one month after the surgery. Marginal and papillary gingiva showed healthy and firm appearance.

\section{Grafted Site Color Matching}

The scores given by three experienced periodontists were better and statistically significant in the test group $(P=0.05, P=0.04, P=0.015)$.

\section{Probing Depth}

There was not any significant difference between the test group and the control group before and after the surgery. They were all in the normal range of $0-3 \mathrm{~mm}$.

\section{Gingival Index}

There was no statistically significant difference between the test and control groups before and after the surgery $(P=1)$.

Table 2. Mean Pain and Discomfort After the Surgery in the Test and Control Groups

\begin{tabular}{lccc}
\hline & Control Group & Test Group & $\boldsymbol{P}$ Value \\
\hline 3 h after surgery & 4.3 & 4.3 & 0.687 \\
24 h after surgery & 2.1 & 0.7 & 0.007 \\
7 days after surgery & 0 & 0.1 & 0.343 \\
\hline
\end{tabular}


Plaque Index

All of the specimens showed a plaque score of $20 \%$ or less.

\section{Discussion}

Tooth root exposure due to the apical migration of gingival margins is defined as gingival recession. Although numerous mucogingival procedures have been proven to be successful in the treatment of this problem, the most common associated technique is the pedicled flap with or without the additive-free connective graft. ${ }^{20}$

The FGG is used to reduce gingival recession and to increase keratinized tissue, but it can cause discomfort in the donor site. Pain is typically present after periodontal surgery. Patients' perception of pain is subjective and varies considerably among different people, ${ }^{20}$ and many pain analgesics are used after periodontal surgery. ${ }^{21}$

Examining all of the test and control cases preoperatively and one month after the surgery, it was revealed that the bleeding index was normal and equal to zero, the gingival index was normal, and the plaque index was below $20 \%$. This reflects the proper patient compliance and the successful elimination of the external factors in the process of healing.

Wound healing is a complex and dynamic process consisting of three overlapping phases. The first phase (inflammatory) begins with tissue damage and takes about 3 to 5 days. In phase II (fibroblastic), the production of tropocollagen and collagen by fibroblasts is present. This period takes about 2 to 3 weeks. The final phase (remodeling) continues for months to years with an unlimited end. At this stage, irregular collagen fibers are destroyed and replaced by new completely regular fibers. ${ }^{22}$ Considering the different stages of wound healing, it seems that LLLT is effective in the fibroblastic stage of wound healing, in which there exists maximum fibroblast activity, angiogenesis, and epithelial proliferation. The effects of the low-level laser on fibroblasts like increased proliferation, maturation, increased secretion of growth factors, and transforming to myofibroblasts have been shown in previous studies. ${ }^{23}$ Complete healing takes about 2 to 4 weeks. ${ }^{24}$

The use of LLLT for healing is a matter of debate, ${ }^{25}$ although better results are expressed in animals ${ }^{26}$ and in vitro studies. ${ }^{27} \mathrm{~A}$ meta-analysis evaluating healing by low-level lasers in 2004 by Woodruff showed healing acceleration in human and animal models. ${ }^{28}$ Another study was conducted using GaAlAs (a wavelength of $670 \mathrm{~nm}, 15 \mathrm{~mW}$ and $4 \mathrm{~J} / \mathrm{cm}^{2}$ per location) but the results were not statistically significant and no relationship was detected. ${ }^{29}$

Secondary healing is described after gingivectomy, and there is a need for 5 weeks for the re-epithelization of gingiva. Several studies have shown the impacts of topical medications, antibiotics, and aminoacids on enhancing secondary healing. ${ }^{30}$

The inflammation of periodontal tissues may be reduced by laser application resulting in adjusting the levels of cytokines, growth factors, and inflammatory mediators. This phenomenon along with the ability to increase cell proliferation and angiogenesis ${ }^{31}$ can increase the color matching speed in the samples, compared to the surrounding tissue. This fact has been described in current and similar studies. ${ }^{32}$

The results of another study demonstrated that the clinical symptoms of inflammation at the site after laser application reduced significantly compared to the control groups, thus recommending that the low-level laser can improve the gingival healing process. ${ }^{33}$

This study demonstrates the potential of LLLT for reducing post-operative pain, which was significant 24 hours after the surgery. These findings were different from those reported by Masse et al, Moslemi et al, and Heidari et al..$^{23,34,35}$ In a systematic review by Bjordal et al, low-level lasers were proved to reduce biochemical markers, oxidative stresses, and edema, leading to pain relief. ${ }^{19}$ They stated that the analgesic effects of LLLT are more efficient in the 72 hours post-surgery when it is irradiated with higher density and with continuous lower doses to accelerate healing. ${ }^{36}$

Depending on the wavelength of the lasers and without any increase in tissue temperature, significant cell activity is present. According to the meta-analysis by Woodruff et al, there are better results by higher energy density (19-24 J/ $\left.\mathrm{cm}^{2}\right)$. However, these results have to be analyzed carefully. ${ }^{28}$ Mitochondrial changes may also occur as a result of positive laser treatment. ${ }^{37}$ The positive mechanism of the laser on various tissues have not been stated clearly, but numerous possibilities have been evaluated, such as the stimulation of porphyrin and cytochromes that cause an increase in cell activity and ATP concentration. ${ }^{37}$ The patients' perception of pain may vary if they anticipate they are exposed to the laser from both sites.

Difficulties in interpreting and comparing studies on the use of low-level lasers as an adjunctive treatment for periodontal surgery is dependent on the lack of fully explained methods and materials and different procedures. Almeida et al reported clinical improvements on day 15 after surgery; however, no significant changes between 2 sides were detected. ${ }^{38}$ Other protocols to evaluate the usage of LLLT in gingival graft healing in humans have to be utilized because of the different clinical results. ${ }^{32}$

Further studies to evaluate the long-term effects of the low-level lasers as a routine periodontal treatment are needed. ${ }^{28}$ The evidence to confirm that applying specific wavelengths of lasers is more efficient than traditional methods is inadequate. Considering the cost, the required time, and the number of clinicians needed, the cooperation of multicenter studies is essential. ${ }^{35}$

The result of the current study indicates the effects of low-level lasers on enhancing healing and reducing the 
post-operative pain of FGGs in donor and recipient sites and a better color match with adjacent tissues. Due to a lack of related studies, further research is needed for this adjunctive method to be confirmed.

\section{Ethical Considerations}

The study design was approved by the ethical committee of Shahid Beheshti University of Medical Sciences (No: 3296, Dated: 02-11-2013).

\section{Conflict of Interests}

The authors declare no conflict of interest.

\section{References}

1. Moghaddas H, Esfahanian V, Moghaddas O. Efficacy of subepithelial connective tissue grafts in the treatment of Miller's Class I and II gingival recessions. Dent Res J (Isfahan). 2011;7:337-353.

2. Prato GP, Clauser C, Tonetti MS, Cortellini P. Guided tissue regeneration in gingival recessions. Periodontol 2000. 1996;11:49-57.

3. Lindhe J, Socransky S, Nyman S, Westfelt E. Dimensional alteration of the periodontal tissues following therapy. Int $J$ Periodontics Restorative Dent. 1986;7:9-21.

4. Sangnes G, Gjermo P. Prevalence of oral soft and hard tissue lesions related to mechanical tooth-cleansing procedures. Community Dent Oral Epidemiol. 1976;4:77-83.

5. Zucchelli G, Cesari C, Amore C, Montebugnoli L, De Sanctis M. Laterally moved, coronally advanced flap: a modified surgical approach for isolated recession-type defects. J Periodontol. 2004;75:1734-41.

6. Bittencourt S, Del Peloso Ribeiro É, Sallum EA, Sallum AW, Nociti FH Jr, Casati MZ. Comparative 6-month clinical study of a semilunar coronally positioned flap and subepithelial connective tissue graft for the treatment of gingival recession. J Periodontol. 2006;77:174-81.

7. Harris RJ, Harris AW. The coronally positioned pedicle graft with inlaid margins: a predictable method of obtaining root coverage of shallow defects. Int J Periodontics Restorative Dent. 1994;14:228-41.

8. Wang C-Y, Tsai S-C, Yu M-C, Lin Y-F, Chen C-C, Chang P-C. Light-Emitting Diode Irradiation Promotes Donor Site Wound Healing of the Free Gingival Graft. J Periodontol. 2015;86:674-81.

9. Löe H, Ånerud Å, Boysen H. The Natural History of Periodontal Disease in Man: Prevalence, Severity, and Extent of Gingival Recession. J Periodontol. 1992;63:48995.

10. Serino G, Wennström JL, Lindhe J, Eneroth L. The prevalence and distribution of gingival recession in subjects with a high standard of oral hygiene. J Clin Periodontol. 1994;21:57-63.

11. Miller P Jr. Root coverage using the free soft tissue autograft following citric acid application. II. Treatment of the carious root. Int J Periodontics Restorative Dent. 1983;3:38-51.

12. Miller PD. Root coverage grafting for regeneration and aesthetics. Periodontol 2000. 1993;1:118-27.

13. Sullivan H, Atkins JH. Free autogenous gingival grafts. 3 . Utilization of grafts in the treatment of gingival recession.
Periodontics. 1968;6:152-60.

14. Miller Jr P. A classification of marginal tissue recession. Int J Periodontics Restorative Dent. 1985;5:8-13.

15. Mester E, Szende B, Tota J. Effect of laser on hair growth of mice. Kiserl Orvostud. 1967;19:628-31.

16. Mester E, Szende B, Spiry T, Scher A. Stimulation of wound healing by laser rays. Acta Chir Acad Sci Hung. 1971;13:31524.

17. Griffin TJ, Cheung WS, Zavras AI, Damoulis PD. Postoperative complications following gingival augmentation procedures. J Periodontol. 2006;77:2070-9.

18. Mester E, Nagylucskay S, Doklen A, Tisza S. Laser: PhotoBiomodulation. Acta Chir Acad Sci Hung. 1976;17:49-55.

19. Bjordal JM, Couppé C, Chow RT, Tunér J, Ljunggren EA. A systematic review of low-level laser therapy with locationspecific doses for pain from chronic joint disorders. Aust $J$ Physiother. 2003;49:107-16.

20. Pilatti GL, André dos Santos F, Bianchi A, Cavassim R, Tozetto CW. The use of celecoxib and dexamethasone for the prevention and control of postoperative pain after periodontal surgery. J Periodontol. 2006;77:1809-14.

21. Harris RJ, Miller R, Miller LH, Harris C. Complications with surgical procedures utilizing connective tissue grafts: a follow-up of 500 consecutively treated cases. Int $J$ Periodontics Restorative Dent. 2005;25:448-459.

22. Murray MD, Brater DC. Adverse effects of nonsteroidal anti-inflammatory drugs on renal function. Ann Intern Med. 1990;112:559-60.

23. Moslemi N, Heidari M, Fekrazad R, Nokhbatolfoghahaie $\mathrm{H}$, Yaghobee S, Shamshiri A, et al. Effect of $660 \mathrm{~nm}$ low power laser on pain and healing in palatal donor sites a randomized controlled clinical trial. J Dent Med. 2014;27:71-7.

24. Aykol G, Baser U, Maden I, Kazak Z, Onan U, TanrikuluKucuk S, et al. The effect of low-level laser therapy as an adjunct to non-surgical periodontal treatment. $J$ Periodontol. 2011;82:481-8.

25. Singer AJ, Clark RA. Cutaneous wound healing. N Engl J Med. 1999;341:738-46.

26. Yu W, Naim JO, Lanzafame RJ. The effect of laser irradiation on the release of bFGF from 3T3 fibroblasts. J Photochem Photobiol. 1994;59:167-70.

27. Del Pizzo M, Modica F, Bethaz N, Priotto P, Romagnoli R. The connective tissue graft: a comparative clinical evaluation of wound healing at the palatal donor site. J Clin Periodontol. 2002;29:848-54.

28. Woodruff LD, Bounkeo JM, Brannon WM, Dawes KS, Barham CD, Waddell DL, et al. The efficacy of laser therapy in wound repair: a meta-analysis of the literature. Photomed Laser Surg. 2004;22:241-7.

29. Damante CA, Greghi SL, Sant'Ana AC, Passanezi E, Taga R. Histomorphometric study of the healing of human oral mucosa after gingivoplasty and low-level laser therapy. Lasers Surg Med. 2004;35:377-84.

30. Vieira J, Lopes CB, DeMarco AC, de Melo Filho AB, Jardini MAN. Clinical study of laser biomodulation (650 $\lambda$ ) after free gingival grafts. J Oral Laser Appl. 2010;10:159-63.

31. Ahad A, Tasneem S, Lamba AK, Khan S. Healing of selfinflicted thermal injury of palatal mucosa by low-level laser therapy. Spec Care Dentist. 2017;37:314-7.

32. Pereira AN, Eduardo CdP, Matson E, Marques MM. 
Effect of low-power laser irradiation on cell growth and procollagen synthesis of cultured fibroblasts. Lasers Surg Med. 2002;31:263-7.

33. Assaf M, Yilmaz S, Kuru B, Ipci SD, Noyun U, Kadir T. Effect of the diode laser on bacteremia associated with dental ultrasonic scaling: a clinical and microbiological study. Photomed Laser Surg. 2007;25:250-6.

34. Heidari M, Paknejad M, Jamali R, Nokhbatolfoghahaei H, Fekrazad R, Moslemi N. Effect of laser photobiomodulation on wound healing and postoperative pain following free gingival graft: A split-mouth triple-blind randomized controlled clinical trial. $J$ Photochem Photobiol B. 2017;172:109-14
35. Masse JF, Landry R, Rochette C, Dufour L, Morency $R$, d'Aoust P. Effectiveness of soft laser treatment in periodontal surgery. Int Dent J. 1993;43:121-7.

36. Maiya GA, Kumar P, Rao L. Effect of low-intensity heliumneon (He-Ne) laser irradiation on diabetic wound healing dynamics. Photomed Laser Surg. 2005;23:187-90.

37. Ahad A, Tandon S, Lamba AK, Faraz F, Anand P, Aleem A. Diode laser-assisted excision and low-level laser therapy in the management of mucus extravasation cysts. J Lasers Med Sci. 2017;8:155-9.

38. Almeida AL, Esper LA, Sbrana MC, Ribeiro IW, Kaizer RO. Utilization of low-intensity laser during healing of free gingival grafts. Photomed Laser Surg. 2009;27:561-4. 